\title{
Keystones in Hypercholesterolemia Treatment Epidemiology
}

Andreia Assis Loures Vale, Lisia Marcilio Rabelo, Anita Saldanha, André Luis Valera Gasparoto, Ana Paula Pantoja Margeotto, Henrique Andrade Rodrigues da Fonseca, Irina Antunes, Tania Leme da Rocha Martinez*

Department of Nephrology, BP - A Beneficência Portuguesa de São Paulo, Brazil

*Corresponding author: Tania Leme da Rocha Martinez, Department of Nephrology, BP - A Beneficência Portuguesa de São Paulo, São Paulo, Brazil.

Received Date: February 13, 2020

Published Date: February 20, 2020

\begin{abstract}
Pharmacological treatments for hypercholesterolemia have come with clinical trials confirming their benefits for decades. This review points to some of them only for the sake of the rational of this paper, focusing mainly on statins and PCSK 9 inhibitors. This review intends to describe not only drug but also lifestyle and interventional trials. As such, the examples of The Seven Countries Study, Framingham Study, MRFIT (Multiple Risk Factor Intervention Trial), Helsinki Heart Study, The Lifestyle Heart Study, SCOR, POSCH - Surgical Control Program of Hyperlipidemias, CLAS - Study on Cholesterol Reduction in Atherosclerosis, MARS - Follow-up study on Atherosclerosis Regression, FATS - Study on the Treatment of Familial Atherosclerosis, ACAPS (Asymptomatic Carotid Artery Progression Study), PLAC (Pravastatin, Lipids and Atherosclerosis in Carotid), Lipid Research Clinics Primary Prevention Trial, Coronary Drug Project, Who Study, BIP Study, Helsinki Heart Study, BECAIT Trial, EXCEL Trial, CARE Trial, 4S Trial, WOSCOPS Trial, ODISSEY Trial, and the HAUSER-CT Trial. In view of all these evidences treating high cholesterol is a priority not only in secondary but in primary prevention too. One should also remember that the cost of coronary treatment should include all procedures inherent to the evolution of the disease, such as: hospital admissions, cardiac catheterization, angioplasty, myocardial revascularization surgery and heart disease rehabilitation, among others, without forgetting the damage caused by the removal of these patients from work.

Keywords: Hypercholesterolemia treatment; Epidemiology; Cholesterol trials; Familial hypercholesterolemia; Statins; PCSK9 inhibitors; Fibrates Abbreviations: AMI: Acute Myocardial Infarction; CAD: Coronary Artery Disease; FH: Familial Hypercholesterolemia; MRFIT: Multiple Risk Factor Intervention Trial
\end{abstract}

\section{Introduction}

Medical treatments are traditionally evaluated by three criteria: efficacy, clinical efficiency and safety. Currently, when using a highcost therapy, should we add another question: can it be paid for by a health social insurance or system? Is your cost-benefit assessment favorable? [1-4]. In the last two decades, the predominant role cholesterol plays in the onset, development and/or worsening of atherosclerosis has been well demonstrated and the large clinical/ epidemiological studies have shown us that the reduction in serum cholesterol levels (more specifically LDL-c) and prevention for coronary artery disease (CAD) would be synonymous.

\section{Study of the seven countries $[5,6]$}

There was a correlation between mean cholesterolemia levels of different populations and mortality rates due to CDD; through this study, it was possible to highlight the relationship between serum cholesterol level and fat intake in food (particularly those rich in saturated fatty acids).

\section{Framingham study}

evidenced the importance of cholesterolemia level in normal individuals in the future development of complications of atherosclerotic disease (prospective research) [7]. 


\section{MRFIT (Multiple Risk Factor Intervention Trial) or Intervention study on multiple risk factors [8]}

Over a period of more than six years, a follow-up was performed on more than 360,000 patients in the United States to define and study the behavior of the main coronary risk factors; this same study also demonstrated the negative relationship between CAD and HDL-c and positive between LDL-c and CAD. The PROCAM $[9,10]$ study unequivocally demonstrated the confirmation of the numerous other benefits from reducing hypertriglyceridemia regarding other risk factors for coronary artery disease, showing us the importance of treatment of this type of dyslipidemia. When we refer to the cost/benefit ratio of dyslipidemia treatment, aiming at prevention for CAD, it is important that we separate primary prevention from secondary prevention.

\section{Primary prevention}

The following studies deserve to be highlighted:

- $\quad$ Oslo study [11] - dietary intervention.

- $\quad$ LRC-CPPT study (The Lipid Research Clinic - Coronary Primary Prevention Trial)12 -drug/cholestyramine intervention.

- $\quad$ Helsinki Heart Study13 - drug intervention/gemfibrozil.

\section{Secondary prevention}

In the numerous studies conducted to demonstrate the benefit of reducing serum cholesterol levels in patients already with atherosclerotic disease, we obtained regression of atherosclerotic injury, regardless of lipid therapy used, and reduction of the progression of coronary artery disease, with a significant decrease in clinical events.

\section{Main Studies}

\section{The lifestyle heart study $[14,15]$}

Prospective, randomized and controlled study, which aimed to prove whether lifestyle changes would be sufficient to alter arterial lesions already evidenced in hemodynamic evaluations; after one year of follow-up, regression in the diameter of the lesion of about $2 \%$, with important clinical benefits (reduction of about $92 \%$ in the frequency of anginous episodes, $42 \%$ in the duration of seizures and $28 \%$ in the severity of the lesions) showed us).

\section{Angiographic studies [16]}

- SCOR- Intervention Study of the Specialized Research Center on Atherosclerosis in San Francisco [17] used patients with heterozygotic familial hypercholesterolemia (FH), of both sexes, with coronary lesions defined by examination quantitative angiographic, which were submitted to appropriate diet and medications (colestipol, niacin and lovastatin) for 26 months.

- POSCH- Surgical Control Program of Hyperlipidemias [18] 399 patients underwent partial ileal by-pass surgery, with follow-up for 10 years.
- $\quad$ CLAS- Study on Cholesterol Reduction in Atherosclerosis [19] randomized, placebo-controlled study, with 162 patients followed for two years through coronary angiography; the groups were treated with diet + niacin or colestipol; it is important to emphasize that individuals were not hypercholesterolemic.

- MARS- Follow-up study on Atherosclerosis Regression [20] prospective, randomized, double-blind, lasting two years, where 270 patients received diet + placebo or lovastatin.

- $\quad$ FATS- Study on the Treatment of Familial Atherosclerosis $[17,21] 146$ men underwent dietary and drug treatment for 2 and a half years, divided into groups that received colestipol more niacin or more lovastatin or more placebo. The contrast between the modest anatomical regression reported $(1-2 \%)$ and the significant reduction of clinical events (50-70\%) it seems justified by the stabilization of atherosclerotic plates caused by treatment and by the subsequent improvement in the motor function of the vessel. We also found that the degree of regression achieved was similar, both in patients with low total cholesterol and/or LDL-c, and in those in which these levels were high in the baseline period. Paraphrasing Dr. Robert Vogel: "Such data reinforce the argument that if a patient presents atherosclerosis (symptomatic), their cholesterol is too high, whatever the level recorded. Cholesterol reduction affects the natural history of the disease." It is essential to mention the clinical studies conducted with noninvasive evaluations (B-mode Ultrasound), which also allowed the monitoring and determination of treatment effects on the incidence of important new atherosclerotic events in the groups evaluated: ACAPS (Asymptomatic Carotid Artery Progression Study) [22] primary prevention/lovastatin and PLAC (Pravastatin, Lipids and Atherosclerosis in Carotid) $[23,24]$ secondary prevention. The evaluation of the benefit of dyslipidemia treatment, according to the drugs used, is another important approach to be made; we will cite some of the most important studies

1. Bile Acid Sequesters- Resins "Lipid Research Clinics Primary Prevention Trial"12: demonstrated the ability of these drugs to reduce coronary events by $19 \%$ after seven years.

2. Nicotinic Acid - Niacin "Coronary Drug Project"25,26 (USA - follow-up for 15 years): the use of this class of drugs was associated with a reduction in mortality from myocardial infarction by $15 \%$ and a $20 \%$ reduction in the occurrence of new events in patients with prior AMI (Acute myocardial infarction).

\section{Fibrates}

- Who study [27]: demonstrated an increase in overall mortality with clofibrate, in addition to its outstanding lithogenic effect. The Bezafibrate Infarction Prevention Study(BIP) [28,29] showed the efficacy of bezafibrate (400 $\mathrm{mg}$ ) in reducing the incidence of CDD in hypercholesterolemic men; also discussed the important role of reducing triglyceride levels and increasing HDL-c levels, also showing its effect on fibrinogen levels and its relationship with other classical risk factors (gender, age, etc.). 
- Helsinki heart study [13]: used gemfibrozil; evidenced also the effect on the reduction of fibrinogen in addition to improving lipoprotein profile.

- Bezafibrate coronary atherosclerosis intervention trial (BECAIT) [30]: used bezafibrate at the dose of $600 \mathrm{md} /$ day, obtaining reduction of cardiovascular events and progression of atherosclerotic lesions in post-AMI patients, in addition to the effects of total cholesterol reduction, LDL-c, triglycerides, fibrinogen and increased HDL-c.

\section{Statins}

- $\quad$ EXCEL (Expanded Clinical Evaluation of Lovastatin) [31]: 8,245 patients with moderate hypercholesterolemia, followed by 48 weeks, were treated with lovastatin, with a decrease in LDL-c from 20 to $40 \%$.

- $\quad 4 S$ - Scandinavian simvastatin survival study [32]: it was a randomized study of 4,444 patients with CAD and cholesterol between 213 - $310 \mathrm{mg} / \mathrm{dL}$; the drug used was simvastatin, at a dose of 20 to $40 \mathrm{mg} /$ day, and the follow-up time was 5.4 years. Its most important results: a reduction in total mortality of $30 \%$ and mortality from coronary heart disease of $42 \%$, with a decrease in total cholesterol levels by $28 \%$ and LDL-col by $38 \%$.

- WOSCOPS- The West of Scotland Coronary Prevention Study [16, 33]: involved 6,595 men aged 45 - 64 years with cholesterol levels at $272+23 \mathrm{mg} \%$, who received pravastatin at a dose of $40 \mathrm{mg} /$ day or placebo. None of the patients had signs and/ or history of coronary heart disease and the mean segment time was 4.9 years. It showed a 31\% reduction in the risk of non-fatal myocardial infarction and $22 \%$ on total mortality, with an average decrease in cholesterol in $20 \%$ and LDL-col by $26 \%$; these results have already been evidenced from the sixth month of treatment.

- CARE- Cholesterol and Recurrent Event: the study was conducted in patients who had non-medication-prone cholesterol levels by the usual consensus. Participants were 4,159 patients in this double-blind study (576 women) who had myocardial infarction with total cholesterol levels below $240 \mathrm{mg}$-dl (mean 209) and LDL-c ranging from 115 to 174 mg-dl (mean 139). The primary objective of the study was to compare the impact on fatal or non-fatal coronary events. All evaluation indexes of the primary endpoint showed a significant reduction in relation to the treated group. The frequency of stroke was also significantly reduced by $31 \%$. There were no significant differences between total mortality and mortality from non-cardiovascular diseases. Pravastatin reduced the rate of coronary events more among women than men; the reduction was also higher in patients with higher pre-treatment values of LDL-c [34]. In addition to the usual hypocholesterolemia drugs, new drugs called PCSK9 inhibitors, mononuclear antibodies capable of reducing LDL-C by about $60 \%$, and can be used primarily in high-risk patients who have not met their goals as well as in individuals with FH and LDL-C still very high, in addition to conventional treatment [35]. It is noteworthy that, together with the changes in values meta this update already in the Guideline also innovated when launching an application with all stages for cardiovascular risk stratification, setting therapeutic goals and guiding the measurements therapies themselves. Many other trials have confirmed the abuse mentioned [36].

\section{PCSK9 inhibitor}

The diagnosis of $\mathrm{FH}$ should be based on serum lipid levels, especially LDL-C (>190 mg/dL), adults, family history, physical examination findings, when present, and genetic testing of mutations in genes associated with the condition.

\section{Odissey}

After a median follow-up of 2.8 years of almost 19,000 participants in the ODYSSEY Outcomes study, patients who received $75 \mathrm{mg}$ or $150 \mathrm{mg}$ fortnightly injections decreased by $15 \%$ in the primary outcome of time for the first occurrence of death from coronary heart disease, non-fatal myocardial infarction, ischemic stroke, or hospitalization for unstable angina, compared to those receiving placebo [37]. Currently patients actively participate in access to treatment due to its very high cost. Specific training has been given annually to health teams and patient associations, as occurs in the Familial Hypercholesterolemia Association. Involve the patient no longer only in the orientation of his or her treatment, as well as in his associations with demands and actions with health policies as a governmental function.

\section{Hauser}

Trial assessing efficacy, safety and tolerability of PCSK9 inhibition in pediatric subjects with genetic LDL disorders (HAUSER-RCT). A study to evaluate the effect of 24 weeks of subcutaneous evolocumab compared with placebo, when added to standard of care, on percent change from baseline in low-density lipoprotein cholesterol (LDL-C) in pediatric subjects 10 to 17 years of age with $\mathrm{HeFH}$ [38].

\section{Conclusion}

The publication of The West of Scotland Coronary Prevention Study (WOSCOPS) in 1995 showed the efficacy of primary prevention in reducing coronary events and total mortality. The high cost of treatment, a fact still used as a hindrance for insurance institutions of the type of the prevention falls by short when we analyze evidence showing that 1 in 4 Americans suffers from cardiovascular disease and that the estimated cost of medical care and disabilities is $\$ 117.4$ billion, while costs related to treatment with lipid-lowering drugs, depending on the drug used, range from $\$ 10$ to $\$ 200$, with a monthly average of $\$ 80$. The Scandinavian Study$4 \mathrm{~S}$, specially designed to verify the effect of treatment/reduction of hypercholesterolemia on overall mortality, left no doubt regarding the positive pending balance in favor of benefit in relation to cost in secondary prevention. The recent publication of the results of 
the CARE study (October 3, 1996) demonstrated the benefit of cholesterol-reducing therapy when extended to most patients with coronary disease at usual cholesterol levels, with greater emphasis on in the female subgroup.

One should also remember that the cost of coronary treatment should include all procedures inherent to the evolution of the disease, such as: hospital admissions, cardiac catheterization, angioplasty, myocardial revascularization surgery and rehabilitation heart disease, among others, without forgetting the damage caused by the removal of these patients from work. In view of the above, there is no doubt about the need and importance of the treatment of hypercholesterolemia in primary prevention and cholesterolemia in secondary prevention.

\section{Acknowledgment}

None.

\section{Conflicts of Interest}

No conflict of interest.

\section{References}

1. Deedvania PC (1995) Clinical perspectives on primary and secondary prevention of coronary atherosclerosis. Med Clin North Am 79(5): 973998.

2. Martens LL, Guibert R (1994) Cost-effectiveness analysis of lipidmodifying therapy in Canada: comparison of HMG-CoA reductase inhibitors in the primary prevention of coronary heart disease. Clin Ther 16(6): 1052-1062.

3. Plans Rubió P, Rovira Forns J (1995) [Cost-effectiveness of pharmacologic treatments for the reduction of blood lipids]. Med Clin (Barc) 105(9): 327-333.

4. Kinlay S, O'Connell D, Evans D (1994) The cost-effectiveness of different blood-cholesterol-lowering strategies in the prevention of coronary heart disease. Aust J Public Health 18(1): 105-110.

5. Keys A (1980) Seven Countries: A multivariate analysis of death and coronary heart disease. Harvard University, Cambridge, USA, pp. 381.

6. (1981) The diet and all-causes death rate in the Seven Countries Study. Lancet 2(8237): 58-61.

7. Kannel WB, Castelli WP, Gordon T (1979) Cholesterol in the prediction of atherosclerotic disease. New perspectives based on the Framingham study. Ann Intern Med 90(1): 85-91.

8. (1990) Mortality rates after 10.5 years for participants in the Multiple Risk Factor Intervention Trial. Findings related to a priori hypotheses of the trial. The multiple risk factor intervention trial research group. JAMA 263(13): 1795-1801.

9. Assmann G, Schulte H, Cullen P, Seedorf U (2007) Assessing risk of myocardial infarction and stroke: new data from the Prospective Cardiovascular Münster (PROCAM) study. Eur J Clin Invest 37(12): 925932.

10. Assmann G, Schulte H (1992) Relation of high-density lipoprotein cholesterol and triglycerides to incidence of atherosclerotic coronary artery disease (the PROCAM experience). Prospective Cardiovascular Münster study. Am J Cardiol 70(7): 733-737.

11. Hjermann I, Velve Byre K, Holme I (1981) Effect of diet and smoking intervention on the incidence of coronary heart disease. Report from the Oslo Study Group of a randomised trial in healthy men. Lancet 2(8259): $1303-1310$
12. (1984) The Lipid Research Clinics Coronary Primary Prevention Trial results. II. The relationship of reduction in incidence of coronary heart disease to cholesterol lowering. JAMA 251(3): 365-374.

13. Frick MH, Elo O, Haapa K, Heinonen OP, Heinsalmi P, et al. (1987) Helsinki heart study: primary-prevention trial with gemfibrozil in middle-aged men with dyslipidemia. Safety of treatment, changes in risk factors, and incidence of coronary heart disease. N Engl J Med 317(20): 1237-1245.

14. Ornish D, Brown SE, Scherwitz LW, Billings JH, Armstrong WT, et al. (1990) Can lifestyle changes reverse coronary heart disease? The lifestyle heart trial. Lancet 336(8708): 129-133.

15. Ornish D, Scherwitz LW, Billings JH, Brown SE, Gould KL, et al. (1998) Intensive lifestyle changes for reversal of coronary heart disease. JAMA 280(23): 2001-2007.

16. Sacks FM, Pfeffer MA, Braunwald E (1995) A Symposium: Cholesterol - lowering trials: new results and emerging issues. Am J Cardiol 76(9 Supp 1): 1C-126C

17. Brown BG, Zhao XQ Sacco DE (1993) Lipid lowering and plaque regression: New insights into prevention of plaque disruption and clinical events in coronary disease. Circulation 87(6): 1781-1791.

18. Buchwald H, Varco RL, Matts JP, Long JM, Fitch LL, et al. (1990) Effect of partial ileal bypass surgery on mortality and morbidity from coronary heart disease in patients with hypercholesterolemia. Report of the Program on the Surgical Control of the Hyperlipidemias (POSCH). N Engl J Med 323(14): 946-955.

19. Blankenhorn DH, Nessim SA, Johnson RL, Sanmarco ME, Azen SP, et al. (1987) Beneficial effects of combined colestipol-niacin therapy on coronary atherosclerosis and coronary venous bypass grafts. JAMA 257(23): 3233-3240.

20. Blankenhorn DH, Azen SP, Kramsch DM, Mack WJ, Cashin-Hemphill L, et al. (1993) Coronary angiographic changes with lovastatin therapy: The Monitored Atherosclerosis Regression Study (MARS). Ann Intern Med 119(10): 969-976.

21. Brown BG, Hillger L, Zhao XQ (1995) Types of change in coronary stenosis severity and their relative importance in overall progression and regression of coronary disease. Observations from the FATS Trial. Familial Atherosclerosis Treatment Study. Ann N Y Acad Sci 748(1): 407417.

22. Furberg CD, Adams HP Jr, Applegate WB, Byington RP, Espeland MA, et al. (1994) Effect of lovastatin on early carotid atherosclerosis and cardiovascular events. Asymptomatic Carotid Artery Progression Study (ACAPS) Research Group. Circulation 90(4): 1679-1687.

23. (1993) The Pravastatin Multinational Study Group for Cardiac Risk Patients. Effect of pravastatin in patients with serum total cholesterol levels from 5,2 to 7,8 $\mathrm{mmol} /$ liter (200 to $300 \mathrm{mg} / \mathrm{dl}$ ) plus two additional atherosclerotic risk factors. The Pravastatin Multinational Study Group for Cardiac Risk Patients. Am J Cardiol 72(14): 1031-1037.

24. Furberg CD, Byington RP, Crouse JR (1994) Pravastatin, lipids, and major coronary events. Am J Cardiol 73(15): 1133-1134.

25. (1975) Clofibrate and niacin in coronary heart disease. JAMA 231(4): 360-381.

26. Canner PL, Berge KG, Wenger NK, Stamler J, Friedman L, et al. (1986) Fifteen-year mortality in Coronary Drug Project patients: long-term benefit with niacin. J Am Coll Cardiol 8(6): 1245-1255.

27. (1980) W.H.O. cooperative trial on primary prevention of ischaemic heart disease using clofibrate to lower serum cholesterol: mortality follow-up. Report of the Committee of Principal Investigators. Lancet 2(8191): 379-385.

28. Barasch E, Benderly M, Graff E, Behar S, Reicher-Reiss H, et al. (1995) Plasma fibrinogen levels and their correlates in 6457 coronary heart disease patients. The Bezafibrate Infarction Prevention (BIP) Study. J Clin Epidemiol 48(6): 757-765. 
29. Manninen V, Elo MO, Frick MH, Haapa K, Heinonen OP, et al. (1988) Lipid alterations and decline in the incidence of coronary heart disease in the Helsinki Heart Study. JAMA 260(5): 641-651.

30. Ericsson CG, Hamsten A, Nilsson J, Grip L, Svane B, et al. (1996) Angiographic assessment of effects of bezafibrate on progression of coronary artery disease in young male postinfarction patients. Lancet 347(9005): 849-853.

31. Bradford RH, Shear CL, Chremos AN, Dujovne C, Downton M, et al. (1991) Expanded Clinical Evaluation of Lovastatin (EXCEL) study results: I Efficacy in modifying plasma lipoproteins and adverse event profile in 8245 patients with moderate hypercholesterolemia. Arch Intern Med 151(1): 43-49.

32. (1994) Randomised trial of cholesterol lowering in 4444 patients with coronary heart disease: the Scandinavian Simvastatin Survival Study (4S). Lancet 344(8934): 1383-1389.

33. Shepherd J, Cobbe SM, Ford I, Isles CG, Lorimer AR, et al. (1995) Prevention of coronary heart disease with pravastatin in men with hypercholesterolemia. West of Scotland Coronary Prevention Study Group. N Engl J Med 333(20): 1301-1307.

34. Sacks FM, Pfeffer MA, Moye LA, Rouleau JL, Rutherford JD, et al. (1996) The effect of pravastatin on coronary events after myocardial infarction in patients with average cholesterol levels. Cholesterol and Recurrent Events Trial investigators. N Engl J Med 335(14): 1001-1009.
35. Karatasakis A, Danek BA, Karacsonyi J, Rangan BV, Roesle MK, et al. (2017) Effect of PCSK9 inhibitors on clinical outcomes in patients with hypercholesterolemia: a meta-analysis of 35 randomized controlled trials. J Am Heart Assoc 6(12): e006910.

36. Mortensen MB, Nordestgaard BG (2019) Statin use in primary prevention of atherosclerotic cardiovascular disease according to 5 major guidelines for sensitivity, specificity, and number needed to treat. JAMA Cardiol 4(11): 1131-1138.

37. Robinson JG, Farnier M, Kastelein JJP, Roth EM, Taskinen MR, et al. (2019) Relationship between alirocumab, PCSK9, and LDL-C levels in four phase 3 ODYSSEY trials using 75 and $150 \mathrm{mg}$ doses. J Clin Lipidol 13(6): 979-988.

38. Trial Assessing Efficacy, Safety and Tolerability of PCSK9 Inhibition in Paediatric Subjects with Genetic LDL Disorders (HAUSER-RCT). ClinicalTrials.gov Identifier: NCT02392559, National Library of Medicine, USA. 